Religare, ISSN: 19826605, v.16, n.2, dezembro de 2019, p.692-713

\title{
Religião na idade mídia: os elos entre o marketing e a mobilidade religiosa no campo religioso brasileiro contemporâneo
}

\author{
Religion in the media age: the links between marketing and \\ mobility religious in religious field brazilian contemporary
}

Danilo Dourado Guerra ${ }^{1}$ Jailson Silva Lopes ${ }^{2}$

\section{Resumo}

Esse artigo pretende refletir acerca das possíveis relações entre marketing religioso e mobilidade religiosa no que concerne ao campo religioso brasileiro contemporâneo. Nesse empreendimento, temos como metodologia a pesquisa bibliográfica, na qual nos serviremos de referenciais teóricos da sociologia da religião, em conjunto com a análise dos dados do último censo (2010) publicado pelo IBGE. A partir desses subsídios trataremos a hipótese de alguns elos entre marketing religioso e mobilidade religiosa que podem em alguma dimensão nos aproximar de uma resposta. O primeiro elo hipotético a ser vislumbrado toma forma a partir do processo de psicologização do mercado religioso. O segundo elo se estabelece na medida em que a midiatização das promessas que respondem aos problemas do 'aqui e agora', 'deste mundo' tem interferido e atuado como vetor de mobilidade religiosa no Brasil. O terceiro elo, por sua vez, é construído na medida em que a estruturação identitária promovida pelo marketing religioso também se caracteriza como fator de mobilidade religiosa.

Palavras-chave: Religião; Mídia; Marketing; Mobilidade religiosa.

\section{Abstract}

This article intends to reflect on the possible relations between religious marketing and religious mobility regarding the contemporary Brazilian religious field. In this endeavor, our methodology is bibliographic research, in which we

\footnotetext{
${ }^{1}$ Doutorado (2018) e mestrado (2015) em Ciências da Religião pela Pontifícia Universidade Católica de Goiás, com estágio doutoral sanduíche na Università Degli Studi di Padova, Itália (2017). Bacharelado em Teologia pelo Seminário Teológico Batista Nacional - SETEBAN-GO (2009-2011) e pela Faculdade da Igreja Ministério Fama-FAIFA (2012-2012).

2 Doutorando em Filosofia pela UnB, dentro da linha de pesquisa Filosofia da Religião. Possui Mestrado em Filosofia pela Universidade Federal do Rio Grande do Norte (2011). Tem Especialização em Ciências da Religião pela Universidade do Estado do Rio Grande do Norte (2011). É Bacharel em Filosofia pela Universidade Federal do Rio Grande do Norte (2008) e Licenciado em Ciências da Religião pela Universidade do Estado do Rio Grande do Norte (2008).
} 
Religare, ISSN: 19826605, v.16, n.2, dezembro de 2019, p.692-713

will use theoretical references of the sociology of religion, together with the analysis of data from the last census (2010) published by IBGE. From these subsidies we will address the hypothesis of some links between religious marketing and religious mobility that may in some dimension bring us closer to an answer. The first hypothetical link to be glimpsed takes shape from the process of psychologizing the religious market. The second link is established as the mediatization of promises that respond to the problems of 'here and now', 'of this world' has interfered and acted as a vector of religious mobility in Brazil. The third link, in turn, is built to the extent that the identity structure promoted by religious marketing is also characterized as a factor of religious mobility.

Keywords: Religion; Media; Marketing; Religious mobility.

\section{Introdução}

O que está em questão não é Deus, mas igreja, a instituição.

M. de Certeau

Extra-extra! Há propaganda por toda parte. Nossa ambientação social está marcada desde os anos da infância pela publicidade ${ }^{3}$ e pelo marketing (MOREIRA, 2015). Em um 'novo' mundo midiático e midiatizante (MOREIRA, 2012), não conseguimos nos esquivar do processo de marketização da sociedade, nem mesmo dentro dos banheiros públicos (EINSTEIN, 2008). Transitamos dentro de uma dinâmica mercadológica vampirizante (MOREIRA, 2008b). Essa atmosfera descortina um panorama imediatista e competitivo, onde a cada segundo e a cada touchscreen somos bombardeados por informações, propagandas e ofertas de todas as espécies relacionadas a tudo o que diz respeito a nossa vida cotidiana. Estas dinâmicas do mercado passam a figurar como matrizes geradoras de sentido, e, por sua vez, podem ser vistas como núcleos

\footnotetext{
${ }^{3}$ A publicidade "há muito não é apenas um setor da economia encarregado de turbinar as vendas, mas é uma cultura na qual se nasce e se vive uma ambiência que, ao substituir as culturas tradicionais, praticamente se naturalizou" (LEISS, KLINE e JHALLY apud MOREIRA, 2015, p. 385). "A publicidade não visa fundamentalmente vender um determinado produto, mas produzir fidelidades de longo prazo, inculcar o próprio consumo como modo de vida e horizonte da existência. A publicidade "educa" as multidões no apetite insaciável por bens, novas sensações e experiências" (LASCH apud MOREIRA, 2015, p. 385).
} 
Religare, ISSN: 19826605, v.16, n.2, dezembro de 2019, p.692-713

identitários (EINSTEIN, 2008), de um ser humano que se transforma e é transformado a cada passo de sua história.

O âmbito da religião não se isenta dessa tendência. Dentro de uma esfera de readaptações e mutabilidades que envolvem tanto fieis como o próprio sistema religioso, o que compreendemos por religião tem de se adequar as demandas dos sujeitos da atualidade, para que o nexo vital disponibilizado por ela continue a matizar sentido. Nesse contexto mercadológico, onde as marcas contêm significado para nossas vidas, e, que os produtos se tornam parte de nossas identidades, é fácil ver por que as organizações religiosas passam a inventar os seus produtos e serviços como marcas (EINSTEIN, 2008, p. 74). Nessa conjuntura, há um processo de cooptação análogo entre a publicidade 'secular' e o mercado religioso, onde um integra os atributos e potencialidades essenciais do outro (EINSTEIN, 2008).

$\mathrm{Na}$ esfera da economia religiosa ${ }^{4}$, a religião tende a recorrer às estratégias do mercado. Essa estrutura de certa forma adaptativa e cooptativa, alude à gênese do marketing religioso no Brasil da pós-modernidade. Tal invenção publicitária atrai consumidores de todas as vertentes, e, em nossa hipótese, se articula, inclusive, como um fator de mobilidade religiosa. Em nossa concepção, a mobilidade religiosa de alguma maneira se relaciona com o processo de formação identitário fragmentado atual. Nesse contexto, o atual homo religiosus se (re) constrói a partir das ofertas e fragmentos de religiosidade que consome.

Sob essa perspectiva, o último censo (2010) publicado pelo IBGE demonstra uma mudança considerável na configuração do panorama religioso brasileiro. Constatou-se um declínio significativo da população católica, paradoxalmente a um avanço quantitativo da população evangélica e dos sem religião.

\footnotetext{
${ }^{4}$ Esta consiste em: “'todas' as atividades religiosas que acontecem em 'qualquer sociedade', incluindo um 'mercado' de atuais e potenciais adeptos, um conjunto de uma ou mais organizações procurando atrair ou manter adeptos, e a cultura religiosa oferecida por essa(s) organização(ões) (FINKE; STARK apud MOREIRA, 2008, p. 134).
} 
Religare, ISSN: 19826605, v.16, n.2, dezembro de 2019, p.692-713

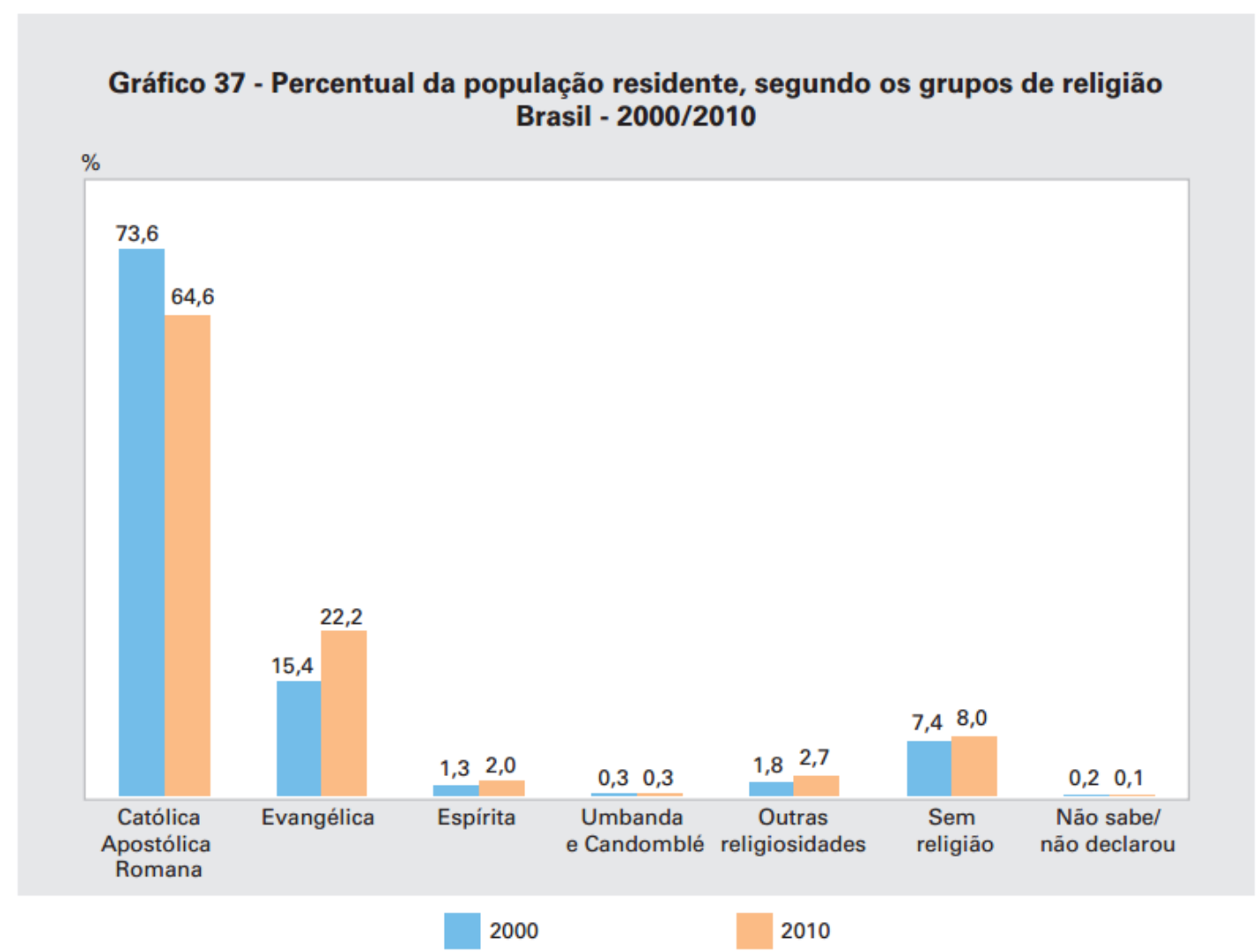

Fonte: IBGE, Censo Demográfico 2000/2010.

Nesse quadro, os católicos passaram de 73,6\% em 2000 para 64,6\% da população em 2010. Em contrapartida os evangélicos ${ }^{5}$ passaram de 15,4\% para 22,2\% da população em uma década. Em números, o aumento populacional evangélico significa aproximadamente 16 milhões de pessoas. Por outro lado, a população que se declarou sem religião passou de quase 12,5 milhões $(7,4 \%)$ para mais de 15 milhões de pessoas (8,0\%). Os adeptos da umbanda e do candomblé mantiveram-se em 0,3\% em 2010. Entre os espíritas, verificou-se a passagem de 1,3\% da população (2,3 milhões) em 2000 para 2,0\% em 2010 (3,8 milhões) (IBGE, $2010, \mathrm{n} / \mathrm{p})$.

Mediante esses dados, o questionamento que suscitamos nesse artigo é: Qual a relação entre o marketing religioso e o processo de mobilidade religiosa

\footnotetext{
${ }^{5}$ Nesse artigo, especificamente, não pretendemos fazer a distinção analítica entre pentecostais e neopentecostais, no que se refere tanto a configuração populacional quanto a práxis de ambas as vertentes evangélicas inseridas no campo religioso. Por questões metodológicas optamos aqui, por reconhecê-las inseridas no mesmo bloco religioso denominado religião evangélica.
} 
Religare, ISSN: 19826605, v.16, n.2, dezembro de 2019, p.692-713

brasileiro? E, se há um elo entre essas esferas sociais, até que ponto o mercado religioso não se apropria de uma estratégia de marketing secular para fomentar novas possibilidades de oferta e por consequência de adesão religiosa?

$\mathrm{Na}$ tentativa de refletir acerca dessa complexa indagação nos fundamentaremos em alguns referenciais teóricos da sociologia da religião (PRANDI, 1997; BAUMAN, 1998; VELHO, 1997; PIERUCCI, 2006; HERVIEULÉGER, 2008; MOREIRA, 2015) para o estabelecimento analítico dos dados do último censo (2010) publicado pelo IBGE. Nesse percurso, de forma parcial e fragmentária consideraremos primeiramente o processo de midiatização da sociedade; em seguida, trataremos acerca do marketing religioso, e por fim, traremos à baila uma síntese dialógica que apresentará prováveis elos entre marketing e mobilidade religiosa instaurados no campo religioso brasileiro contemporâneo. Cientes de toda a labirintização da temática, isto é o que pretendemos anunciar, ou melhor, 'vender' na sequência.

\section{Idade Midia e religião}

Se quisermos fazer um jogo de palavras, podemos dizer que estamos na Idade Mídia. A idade cronotópica da sociedade em que a mídia em todas as suas plataformas dita os parâmetros vitais e existenciais da humanidade. Vivemos numa era intermediada pela (in)formação por um lado, e pela (des)informação, por outro. Hoje, mais que em qualquer período histórico, o domínio midiático das marcas exerce preponderante papel na formação do público, pois como propõe Joana Puntel, “as tecnologias têm o poder de controlar o nosso pensar e, consequentemente, a forma de planejarmos a vida" (PUNTEL, 2005, p. 21).

Como será evidenciado adiante, a relação entre essa midiatização na vida contemporânea não só é inevitável, como atinge todos os campos do viver, inclusive, o religioso. Não se pode pensar religião sem mídia, conforme mostrado na pesquisa analítica de Puntel (apud MOREIRA, 2012, p. 41). Basta ligarmos a tv (em quase todos os canais abertos), e veremos o que não se via há algumas 
Religare, ISSN: 19826605, v.16, n.2, dezembro de 2019, p.692-713

décadas: a mídia como agente evangelizador! O que, em épocas recentes era combatido pela própria igreja, hoje é o seu maior aliado.

Mais do que a simples exposição religiosa nos meios de comunicação, o que chama a nossa atenção são as abordagens com as quais o 'produto' religioso é anunciado. As técnicas empregadas sãos as mesmas utilizadas por grandes empresas, a fim de atrair seu público. Destacamos o verbo atrair, porque a midiatização não apenas anuncia, mas exerce, hoje, a função de introduzir o indivíduo em seu universo cada vez mais amplo, posto que "a presença cada vez mais prolongada de indivíduos em ambientes virtuais, e a própria dinâmica de progressiva virtualização da experiência colocam questões novas e inusitadas também para as ciências da religião" (MOREIRA, 2012, p. 113, grifo nosso).

Na era midiática, praticamente todas as religiões se servem de espaços virtuais, por exemplo, para cooptar fieis, ou apenas curiosos, para seu 'templo', que é posto ali, diante dele. Seja uma transmissão televisiva, que transporta o indivíduo para a 'igreja', ali, no conforto da poltrona da sua sala, ou um site, onde esse indivíduo pode transitar pelos produtos que lhe são oferecidos, deixar um pedido de oração, ou dar uma oferta (indo na aba Doações, onde se vê em destaque o logo dos bancos nos quais a igreja tem conta).

Nessa nova conjectura vivencial trazida pela Idade Mídia, o marketing se faz vetor fundamental. Acerca de suas implicações e relações com o mercado e a religião trataremos a seguir.

\section{Aproximações entre marketing, religião e mercado}

O marketing por sua vez, é um passo a mais em relação à publicidade. Enquanto esta expõe o produto, aquele apela às emoções do cliente, como se verá mais adiante. $\mathrm{O}$ exemplo dos televangelistas ilustra bem essa distinção. Diante desse contexto, Mara Einstein percebe que:

os programas religiosos na televisão são hoje, em essência, 30 minutos de 'infomerciais', pensados para atrair uma ampla 
Religare, ISSN: 19826605, v.16, n.2, dezembro de 2019, p.692-713

audiência de pessoas que estão em busca de religiosidade. Para ser o mais eficiente possível, as mensagens no ar são controladas e manipuladas para terem um apelo amplo [...] Eles (os televangelistas) aprenderam algo que os outros só iriam descobrir mais tarde: a televisão não é meio ideal para apresentar a religião (EINSTEIN apud MOREIRA, 2012, p. 25).

O marketing, portanto, deverá ser a combinação entre o anúncio e a sensação que ele conseguirá provocar nos indivíduos; em outras palavras, podemos chamar de experiência estética (aistetiké = sentir). A experiência estética proporcionada pelo marketing tem como uma de suas principais características fazer o consumidor se sentir importante. $\mathrm{O}$ indivíduo ou grupo sente(m)-se parte integrante do processo de estetização marketológica (EINSTEIN apud MOREIRA, 2012, p. 28-29).

Para ilustrar esse ponto, façamos, de forma análoga, uma relação entre uma das marcas mais famosas do mundo, a Apple, e um texto clássico do pensamento judaico-cristão: o relato de Eva e a maçã. Nessa analogia a redação do texto sagrado que diz: "E fez brotar o eterno Deus, da terra, toda árvore cobiçável à vista [...] E viu a mulher que boa era a árvore para comer, e que desejável era para os olhos e cobiçável..." (Gn 2,9;3,6) e a maçã mordida, símbolo da Apple, ilustra bem o binômio anúncio-desejo.

Esse desejo, que nasce de forma embrionária, se avoluma e se imbrica de múltiplas formas, causando uma mobilidade profana ou religiosa. A tese, por exemplo, que permeia a obra de Mara Einstein, Brands of Faith, mostra convincentemente que não é possível pensar o marketing religioso dissociado da mensagem religiosa; eles jamais se excluem, antes cooperam mutuamente para a consecução de seus objetivos.

Contudo, antes de tratarmos acerca da provável estrutura dialógica envolvendo marketing religioso e mobilidade religiosa, convém a consideração de que em um âmbito de mutações no campo religioso, não é só o fiel quem se movimenta de forma peregrina e subjetivada. Antes de tudo, a dança à procura 
Religare, ISSN: 19826605, v.16, n.2, dezembro de 2019, p.692-713

tanto de sobrevivência quanto de novos horizontes de significações se instala na própria religião.

No entendimento de Moreira (2008a), “a religião não acabou, ela se deslocou". Nesse novo panorama que anuncia um deslocamento ${ }^{6}$ religioso, as próprias conceituações do que seria religião, ou mesmo, campo religioso, demandam revisões ${ }^{7}$ (MOREIRA, 2008a, p. 72). Dito isso, voltamos nossos olhos para o campo religioso brasileiro.

Podemos vislumbrar que dentro do campo religioso brasileiro contemporâneo, há o que Bourdieu (1974) chama de relação circular entre o produto oferecido e a demanda dos leigos. Nele, são travadas as batalhas pelo monopólio do poder religioso. Nesse contexto, são os problemas principalmente de ordem social que enchem o prato das demandas e estabelecem o fluxo das trocas no campo religioso (PRANDI, 1997, p. 64).

Na concepção de Berger (1985), o campo religioso atual é caracterizado pela competição racionalizada de mercado, num quadro histórico inverso, onde quem determina a demanda agora são os consumidores. Nesse palco de ofertas e demandas, "a religião não pode ser mais imposta, mas tem que ser posta no mercado" (BERGER, 1985, p. 156). Nessa conjuntura,

\footnotetext{
6 "Está em processo um verdadeiro deslocamento ou uma transformação do religioso. Outras instituições ou instâncias sociais assumem funções das instituições religiosas no campo cultural, principalmente o complexo midiático-cultural, que envolve televisão, internet, cinema, revistas e literatura, esporte, publicidade e moda. Estas instituições, todas do e para o mercado, também produzem símbolos, sentidos, crenças, explicações sobre o real, rituais e mitos, propõem valores, estilos de vida, figuras para a imitação, a fidelidade e mesmo a devoção das pessoas. Este parece ser um traço fundamental da atual constelação. A religião não deve mais ser procurada apenas em igrejas, templos e terreiros, onde ela se tematiza explicitamente, mas também lá onde ela não se chama de religião: no culto ao dinheiro e ao corpo, na eficiência administrativa e empresarial, no encantamento pela técnica e pelo design, no êxtase sonoro ou imagético, no mundo do esporte, das compras e dos astros midiáticos" (MOREIRA, 2008a, p. 72).

${ }^{7}$ Moreira (2008) já nos alerta acerca do que seria o deslocamento da religião, ou deslocamento religioso. Nesse contexto, "as mudanças de lugar e da própria 'natureza' do religioso apontam para a necessária revisão seja das metodologias aplicadas ao estudo da religião, seja do aparato conceitual com que se costuma circunscrever a experiência religiosa" (MOREIRA, 2008a, p. 70). Isso porque na concepção do autor, "os conceitos de religião ou mesmo de campo religioso se tornaram um cobertor curto: eles não cobrem mais todas as modalidades, os espaços, a diversidade e a mutabilidade da experiência religiosa nos quadros da modernidade capitalista tardia" (MOREIRA, 2008a, p. 72).
} 
ela tem que ser 'vendida' para uma clientela que não está mais obrigada a 'comprar'. A situação pluralista é, acima de tudo, uma situação de mercado. Nela, as instituições religiosas tornam-se agências de mercado e as tradições religiosas tornam-se mercadorias [commodities] de consumo. E, de qualquer forma, grande parte da atividade religiosa nessa situação vem a ser dominada pela lógica da economia de mercado (BERGER apud MOREIRA, 2008, p. 132).

Vivemos inundados por uma nuvem secularizante ${ }^{8}$ e mercadológica que configura um cenário multifacetado e pluralista, onde "os grupos religiosos têm de se organizar de forma a conquistar uma população de consumidores" (BERGER, 1985, p. 150)9 . Nesse quadro, “as religiões têm que se adaptar às subjetividades e individualidades da população, relativizando suas verdades em prol das verdades do consumidor, que hoje se tornou um colecionador de verdades e experiências"' (GUERRA, 2014, p. 116).

Figura-se, assim, uma paisagem de destradicionamento da crença (HERVIEU-LÉGER, 2008), onde, “toda religião tradicional ou majoritária tende andar para traz" (PIERUCCI, 2004, p. 14), ou ao menos rever seus conceitos e estratégias de sobrevivência. Não é à toa que Berger (1985, p. 146), afirma que “a secularização causa o fim dos monopólios das tradições religiosas e assim, ipso facto, conduz a uma situação de pluralismo". Este, por sua vez, aquece o instinto de competição em prol da sobrevivência institucional dentro do campo religioso brasileiro. Essa lógica do mercado é permeada por uma estratégia de marketing religioso, na medida em que consideramos a estrutura análoga entre marketing e religião (EINSTEIN, 2008). Essa relação aponta para alguns prováveis elos entre o marketing e mobilidade religiosa em se tratando do campo religioso do Brasil atual. Isso é o que anunciaremos na sequência.

\footnotetext{
${ }^{8}$ A secularização se constitui em um processo de objetividades e subjetividades, que proporciona ao individuo a sua desfiliação das estruturas institucionais religiosas tendo como aspectos principais a perda do poder moral da religião e na subjetivação das crenças (BERGER, 1985).

9 Porém evitando a competição selvagem, pois esta ao invés de atrair afasta os fregueses (BERGER, 1985).
} 
Religare, ISSN: 19826605, v.16, n.2, dezembro de 2019, p.692-713

\section{Elos entre o marketing e mobilidade religiosa}

No caso do campo religioso brasileiro, entre sobrevivências institucionais e as novas preferências da 'clientela', o primeiro elo hipotético que vislumbramos em relação ao marketing religioso e a mobilidade dos fieis brasileiros é a grande eficácia do que Einsten (2008) chama de processo de psicologização do mercado religioso. Em nossa concepção, tal processo gera empatia do consumidor com a mercadoria e, nesse sentido, fomenta a mobilidade religiosa.

De acordo com Einstein (2008), com o advento da tecnologia e psicologia o foco da publicidade mudou. Atualmente para incitar os consumidores a comprar produtos desnecessários na sua maioria, os anunciantes se tornaram especialistas em psicologia. Nesse contexto, não se vende mais o produto pelo produto, mas sim a experiência. Sob um prisma estratégico, se fornece aos consumidores algo para pensar e sentir sobre um produto ou serviço além de seus atributos físicos. Assim, instaura-se a psicologização como mecanismo de propaganda. Este, em suma, trabalha com a motivação dos sujeitos, com as esperanças, necessidades, medos, crenças, opiniões e atitudes que moldam as ações e as escolhas que uma pessoa faz (EINSTEIN, 2008, p. 68-71).

Sob essa perspectiva, a mobilidade religiosa na cena brasileira atual em alguma dimensão se relaciona com um processo de sensibilização dos fiéis. Do ponto de vista mercadológico, Michael Schudson (apud EINSTEIN, 2008) as mulheres são o alvo principal para a maioria dos produtos de consumo. Estas 'seriam' mais emocionais do que os homens, e, por conseguinte, mais predispostas a apelos emocionais.

Tal afirmativa, com ressalvas a todas as políticas de interpretação social androcêntricas e patriarcais, nos faz refletir um pouco. É razoável a dedução de que esta estratégia de psicologização cooptada pelo campo religioso brasileiro pode ter provocado o crescimento da população evangélica no país. Isso pode ter ocorrido ao passo que segundo o último censo (2010), o perfil populacional evangélico se caracteriza por uma maioria da população feminina. Esta definida 
Religare, ISSN: 19826605, v.16, n.2, dezembro de 2019, p.692-713

por uma faixa etária com maiores percentuais entre as crianças $(25,8 \%$ na faixa de 5 a 9 anos) e adolescentes (25,4\% no grupo de 10 a 14 anos) (IBGE, 2010, n/p).

Tabela 13 - Percentual da população residente, por situação do domicílio e sexo, segundo os grupos de religião - Brasil - 2010

\begin{tabular}{|c|c|c|c|c|c|c|c|c|c|}
\hline \multirow{4}{*}{ Grupos de religiẫo } & \multicolumn{9}{|c|}{ Percentual da população residente } \\
\hline & \multirow{2}{*}{\multicolumn{3}{|c|}{ Total }} & \multicolumn{6}{|c|}{ Situação de domicílio e sexo } \\
\hline & & & & \multicolumn{3}{|c|}{ Urbana } & \multicolumn{3}{|c|}{ Rural } \\
\hline & Total & Homem & Mulher & Total & Homem & Mulher & Total & Homem & Mulher \\
\hline Católica Apostólica Romana & 64,6 & 65,5 & 63,8 & 62,2 & 62,9 & 61,5 & 77,9 & 78,4 & 77,3 \\
\hline Evangelicas & 22,2 & 20,1 & 24,1 & 23,5 & 21,4 & 25,4 & 14,9 & 13,5 & 16,5 \\
\hline De Missão & 4,0 & 3,6 & 4,4 & 4,2 & 3,8 & 4,6 & 3,0 & 2,7 & 3,3 \\
\hline Pentecostal & 13,3 & 12,1 & 14,5 & 13,9 & 12,7 & 15,0 & 10,1 & 9,0 & 11,2 \\
\hline Não determinada & 4,8 & 4,4 & 5,3 & 5,4 & 4,9 & 5,8 & 1,9 & 1,7 & 2,1 \\
\hline Espíritas & 2,0 & 1,7 & 2,3 & 2,3 & 2,0 & 2,7 & 0,2 & 0,2 & 0,3 \\
\hline Umbanda e Candomblé & 0,3 & 0,3 & 0,3 & 0,4 & 0,3 & 0,4 & 0,0 & 0,0 & 0,0 \\
\hline Outras religiosidades & 2,7 & 2,5 & 2,9 & 3,0 & 2,8 & 3,1 & 1,5 & 1,4 & 1,5 \\
\hline Sem religião & 8,0 & 9,7 & 6,4 & 8,5 & 10,4 & 6,8 & 5,3 & 6,2 & 4,3 \\
\hline
\end{tabular}

Fonte: IBGE, Censo Demográfico 2010.

Nota: Os diferenciais para o somatório de $100 \%$ se refere aos registros de pessoas que não sabem ou não declararam a reliqiāo.

Curiosamente, a religião católica que perdeu muitos fieis nesses últimos tempos, é majoritariamente composta por homens. Em contrapartida, esse grau de empatia diante das ofertas do campo religioso, talvez também possa explicar o crescimento da população dos sem religião. Estes, que são em maioria do sexo masculino provavelmente, sob algum aspecto não aderiram, ou não se sensibilizaram com as propostas do mercado e preferiram construir seu próprio caminho, e porque não, outra proposta de religiosidade. Todos esses dados indicam que necessitamos de parâmetros investigativos mais acurados sob a provável relação entre marketing, gênero e mobilidade religiosa.

Por outra parte, outro aspecto que desejamos abordar é que em um contexto dinâmico midiático e mercadológico que envolve o campo religioso, o marketing que promete respostas às demandas cotidianas também se faz um dos vetores de mobilidade religiosa no Brasil pós-moderno.

Habitamos em uma sociedade que não necessita do governo dos deuses, onde nossas inquietações do dia a dia são dirigidas ao âmbito profano (PRANDI, 1997, p. 64). Nessa 'nova' sociedade, as demandas pessoais devem ser 
Religare, ISSN: 19826605, v.16, n.2, dezembro de 2019, p.692-713

solucionadas. Agora, a religião que pretende sobreviver precisa mudar "ela passa a ser sem fronteira e sem território, sem ser, contudo universal e única [...] devendo adaptar-se a novas situações e novas demandas"' (PRANDI, 1997, p. 69) do mercado global. Nesse panorama globalizado e secularizado, que suscita metamorfoses internas no que tange a realidade institucional da religião, esses mecanismos de adaptação podem ser concebidos a partir das estratégias de marketing e propaganda das empresas religiosas. É nesse palco de conflitos e constantes ressignificações que as incertezas humanas hoje são identificadas e tratadas por especialistas 'auto aperfeiçoadores'. É justamente nesse tratamento, que o antigo discurso religioso pré-moderno de fraqueza e penitência, miséria e privação, é substituído pelo da potencialidade e do consumismo (BAUMAN, 1998, p. 221).

Sob esse prisma, na concepção de Guerra (2014, p. 117),

Para se compreender as alterações no campo religioso brasileiro seria necessário olhar mais para as demandas do que para as ofertas das instituições religiosas, mais para os fregueses do que para os vendedores. O panorama religioso brasileiro tem mudado não porque as pessoas têm pensado ontologicamente, mas porque estas migram para o local onde suas demandas mais urgentes da vida cotidiana são atendidas (Bauman, 1998). Estas não se apegam mais ao caráter regulador e hereditário da tradição institucional (Hervieu-Léger, 2008), mas sim ao modelo religioso com suas estruturas plausíveis e eficazes dentro do que Bourdieu (1974) denomina de economia das trocas simbólicas (GUERRA, 2014, p. 117, grifos nossos).

O crescimento da população evangélica no Brasil pode ser analisado à luz desse contexto. Sob essa perspectiva, Velho trata acerca de uma das faces do que ele chama de processo de pentecostalização. Esta face englobaria uma desteologização generalizada com objetivos propondo ao fiel uma libertação com “ênfase pragmática nos resultados, que parece substituir a ênfase clássica em conversão, na mesma medida em que as manifestações substituem os argumentos" (VELHO, 1997, p. 56). 
Religare, ISSN: 19826605, v.16, n.2, dezembro de 2019, p.692-713

Nessa esfera, é "o terreno das contingências, do aqui e agora e do cotidiano que ganha centralidade. Muito além, inclusive, de simples locus dos sinais da salvação em outro mundo" (VELHO, 1997, p. 52). Essa proposta contingencial se propaga em meio às estruturas da mídia nacional, e, a nosso ver, é fator de mobilidade religiosa.

Em contrapartida, num quadro social-religioso de perda de fieis, a estratégia católica tem sido dar "mais espaço ao particularismo das igrejas locais, diminuindo as pretensões centralistas de Roma, por um lado, e transformar a mensagem estritamente teológica em uma proposta de malhas largas de ética pública internacional" (GUIZZARDI apud PACE, 1997, p. 35).

Na era do espetáculo a mobilidade religiosa também se relaciona com as estratégias de marketing das instituições. Um exemplo pontual pode ser visto nas reações e mudanças do catolicismo diante da modernidade. Nas palavras de Rosado-Nunes (2004, p. 23), a igreja teve de se arranjar internamente promovendo modificações pontuais para sobrevivência da instituição, exemplificadas pela oferta de padres cantores e missas-show.

Ainda dentro da análise acerca do marketing que promete respostas imediatas as demandas do cotidiano, cabe-nos uma consideração 'estratigráfica' acerca do potencial de consumo e de sonhos da população brasileira. Segundo último censo, a maioria dos fieis brasileiros se encontram e emergem das classes mais 'baixas'(com todas as ressalvas ao termo) da sociedade. De acordo com os dados, 63,7\% da população religiosa que mais cresce no país (os evangélicos os pentecostais) ganham até um salário mínimo. No âmbito das populações que crescem, $(59,2 \%)$ dos sem religião também ganham até um salário mínimo. Em contrapartida, 55,8\% da população religiosa que mais diminui país (os católicos) também se concentra na faixa de até 1 salário mínimo (IBGE, 2010, n/p). 
Religare, ISSN: 19826605, v.16, n.2, dezembro de 2019, p.692-713

\section{Tabela 19 - Distribuição percentual de pessoas de 10 anos ou mais de idade residentes em domicílios particulares permanentes, por grupos de religião, segundo as classes de rendimento nominal mensal domiciliar per capita Brasil - 2010}

\begin{tabular}{|c|c|c|c|c|c|c|c|c|}
\hline \multirow{3}{*}{$\begin{array}{l}\text { Classes de rendimento nominal } \\
\text { mensal domiciliar per capita } \\
\text { (salário mínimo) } \\
\text { (1) }\end{array}$} & \multicolumn{8}{|c|}{$\begin{array}{l}\text { Distribuição percentual de pessoas de } 10 \text { anos ou mais de idade } \\
\text { residentes em domicílios particulares permanentes, por grupos de religiāo (\%) }\end{array}$} \\
\hline & \multirow[b]{2}{*}{$\begin{array}{l}\text { Católica } \\
\text { Após- } \\
\text { tólica } \\
\text { Romana }\end{array}$} & \multicolumn{3}{|c|}{ Evangélicas } & \multirow[b]{2}{*}{ Espírita } & \multirow[b]{2}{*}{$\begin{array}{l}\text { Umban- } \\
\text { da e } \\
\text { Candom- } \\
\text { blé }\end{array}$} & \multirow[b]{2}{*}{$\begin{array}{c}\text { Outras } \\
\text { religiosi- } \\
\text { dades }\end{array}$} & \multirow[b]{2}{*}{$\begin{array}{l}\text { Sem } \\
\text { religiāo }\end{array}$} \\
\hline & & $\begin{array}{l}\text { De } \\
\text { Missão }\end{array}$ & $\begin{array}{l}\text { De } \\
\text { Origem } \\
\text { Pente- } \\
\text { costal }\end{array}$ & $\begin{array}{c}\text { Não } \\
\text { determi- } \\
\text { nada }\end{array}$ & & & & \\
\hline Total & 100,0 & 100,0 & 100,0 & 100,0 & 100,0 & 100,0 & 100,0 & 100,0 \\
\hline Até $1 / 8$ & 5,0 & 2,3 & 3,8 & 2,1 & 0,4 & 1,7 & 2,6 & 4,4 \\
\hline Mais de $1 / 8$ a $1 / 4$ & 6,7 & 4,2 & 7,0 & 4,7 & 1,2 & 4,1 & 4,5 & 7,3 \\
\hline Mais de $1 / 4$ a $1 / 2$ & 17,0 & 14,2 & 20,5 & 15,9 & 5,1 & 13,2 & 14,2 & 19,6 \\
\hline Mais de $1 / 2$ a 1 & 27,1 & 27,5 & 32,3 & 29,7 & 15,0 & 24,8 & 26,8 & 27,9 \\
\hline Mais de 1 a 2 & 22,4 & 27,1 & 22,5 & 26,0 & 24,9 & 26,3 & 25,0 & 19,6 \\
\hline Mais de 2 a 3 & 7,5 & 9,6 & 5,5 & 8,1 & 15,0 & 10,3 & 8,8 & 5,9 \\
\hline Mais de 3 a 5 & 5,5 & 7,0 & 3,0 & 5,5 & 15,7 & 8,4 & 6,6 & 4,5 \\
\hline Mais de 5 a 10 & 3,6 & 4,0 & 1,2 & 3,0 & 13,2 & 4,9 & 4,7 & 3,4 \\
\hline Mais de 10 & 1,7 & 1,6 & 0,4 & 1,1 & 6,5 & 2,2 & 2,5 & 2,1 \\
\hline Sem rendimento (2) & 3,4 & 2,6 & 3,7 & 3,9 & 2,8 & 4,1 & 4,2 & 5,2 \\
\hline
\end{tabular}

Fonte: IBGE, Censo Demográfico 2010.

(1) Salário mínimo utilizado: $\mathrm{R} \$ 510,00$. (2) Inclusive os domicílios com rendimento domiciliarper capita somente em benefícios.

Sem deixar de considerar a significativa quantidade de fieis que se instalam nas camadas mais altas da sociedade, essa constatação em certa medida estratifica o quadro de mobilidade religiosa do país, ao passo em que a maioria da população se encontra nas camadas mais baixas e necessitadas da sociedade. Aqui, os anseios, demandas e sonhos sociais que não são respondidos são transferidos para o âmbito da religião. Em sua lógica propagandista, o campo religioso se configura como um espaço alternativo de sentidos, realizações e disputas.

Sob esse viés, Prandi (1997), assinala que o crescimento das religiões no contexto moderno está relacionado com a marginalização das populações, é "nesse fosso que progridem as religiões das massas, pelo menos a maioria esmagadora delas; religiões prosperam com a pobreza das populações que ficam social e culturalmente para trás" (PRANDI, 1997, p. 64). Esta é a deixa para que entrem em cena as religiões e suas ofertas especializadas em solucionar problemas, proporcionando os mecanismos de troca entre fiel e sagrado “oferecendo alternativas de cura e estratégias financeiras que funcionam como 
Religare, ISSN: 19826605, v.16, n.2, dezembro de 2019, p.692-713

serviços, nos quais Deus é apenas o meio" (PRANDI, 1997, p. 64). À luz dessa perspectiva, observamos o quadro religioso brasileiro, ainda que de forma não generalizada, se confeccionar sob padrões que englobam a relação entre necessidade dos marginalizados sociais e a propaganda da oferta religiosa social brasileiro.

Por outra parte, outro aspecto que objetivamos enfatizar é que a estruturação identitária promovida pelo marketing religioso em alguma medida também se caracteriza como fator de mobilidade religiosa. Vivemos em um contexto em que as marcas surgem como parte da criação de identidade, como estruturas identitárias. Estas ajudam a definir quem somos. Nesse sentido, as marcas não são apenas as percepções sobre um produto ou serviço, também são pedaços de nossa identidade (EINSTEIN, 2008, p. 72). Nas palavras de Clifton e Maughan,

As marcas tornaram-se muito mais do que os produtos para comprar. Elas se tornaram parte do tecido da nossa sociedade. As marcas são parte do nosso sistema de ordenar as coisas, elas até mesmo criam o contexto sobre quem somos e como vivemos. Elas tornaram-se emblemas para as pessoas. Elas articulam quem você é e quais são seus valores (CLIFTON e MAUGHAN apud EINSTEIN, 2008, p. 72).

Na concepção de Schultz e Schultz (apud EISTEIN, 2008, p. 71), as marcas podem fazer cinco coisas. 1- Criar valor financeiro para o proprietário, tanto a curto e longo prazo. 2- Criar várias formas de valor para os clientes. 3- Criar relações com os empregados e outras partes interessadas. 4- Durar um longo tempo ou, pelo menos, ser lembrada por muito tempo. Isto significa renda de longo prazo. 5- Tornar-se uma parte da cultura. Nesse aspecto, ícones culturais têm grande valor.

Diante dessas informações questionamos: até que ponto o mercado religioso não se apropria dessa estratégia de marketing como fomentadora de novas possibilidades de oferta e por consequência de adesão religiosa? 
Religare, ISSN: 19826605, v.16, n.2, dezembro de 2019, p.692-713

Esse contexto onde a publicidade das marcas fomenta os novos retratos do sujeito da modernidade também se estende ao campo da religião, na medida em que o próprio campo religioso (sob instinto de competição e sobrevivência) igualmente se própria destas estratégias e tendências comerciais. Já afirma Pace (1997), que transitamos um cenário em que a globalização se constitui como "um processo de decomposição e recomposição da identidade individual e coletiva que fragiliza os limites simbólicos dos sistemas de crença e pertencimento" (PACE, 1997, p. 32). Frente a esse cenário, o marketing religioso restaura estruturas identitárias, ainda que estas passem a se constituir em sua maioria a partir de fragmentos que anunciam uma nova face retocada e ressignificada do sujeito religioso.

Nesse âmbito de trocas simbólicas, algo que não pode deixar de ser mencionado é que essa propaganda tem que ser sempre convincente, pois nos tempos de uma religião solvente em meio às reconfigurações identitárias os deuses ainda continuam sendo muitos (PIERUCCI, 2006, p. 114). É dentro dessa lógica de sobrevivência que se estabelecem as estratégias do marketing ${ }^{10}$ religioso.

Nesse quadro as religiões com maior potencial de empatia saem na frente no que se refere à influência sobre os novos retratos dos fieis. Diante desse complexo processo que envolve disputas e estruturas de plausibilidade, as religiões que geram mais identificação também fomentam no indivíduo um fragmento de sua identidade religiosa. Nesse sentido, pressupomos que o atrativo religioso que, de alguma forma contribui para a (re)configuração identitária do fiel brasileiro, se faz agente provocador de significativas alterações no campo religioso do país.

\footnotetext{
${ }^{10}$ Na concepção de Moreira (2015), O marketing e o design fazem parte essencial do processo de construção estético-simbólica da aura das mercadorias, esta entidade metafísica, ou valor simbólico agregado, que está incorporado e representado iconicamente nas marcas (MOREIRA, 2015, p. 386).
} 
Religare, ISSN: 19826605, v.16, n.2, dezembro de 2019, p.692-713

Mas isso não é tudo. Haja vista que essa mobilidade religiosa também se relaciona com o processo de fragmentação identitária dos fieis. Isso ocorre ao passo que os dados do censo esbarram no fator da religiosidade sincrética e peregrina, e nesse aspecto, não nos permite traçar um perfil monolítico no que tange às novas identidades religiosas no Brasil.

Mediante essa atmosfera midiatizante, o atual homo religiosus brasileiro se (re)constrói e se identifica a partir das ofertas e fragmentos de religiosidade que consome. Nesse campo católicos e evangélicos (re)configuram seus retratos identitários. Este novo quadro pinta um significativo crescimento suposta identidade evangélica, e, em contrapartida o declínio confessional, seguido de uma tentativa de reafirmação de uma 'identidade religiosa' dantes hegemônica (caso do catolicismo).

Algo significativo a ser salientado, é que em meio a essa dinâmica competitiva de mercado, as estratégias de publicidade e marketing religioso além de atuarem como estruturantes identitários também fomentam plataformas de lealdade religiosa. Em outras palavras, a marketização do campo religioso brasileiro tende a gerar um processo de fidelização que se diagrama, conforme Moreira (2008a), em um sistema identitário cada vez mais complexo e competitivo $^{11}$.

Nesse contexto, no âmbito do mercado,

A marca existe para criar lucros. Isso é feito através da criação de lealdade entre os seus clientes. Essa lealdade reduz os custos de marketing dos produtores, porque os consumidores (legalistas de marca) tornam-se compradores de repetição (em série, a longo prazo) do produto. Nesse processo, os comerciantes simplesmente tem que lembrar os consumidores a continuar comprando a marca a longo prazo (EINSTEIN, 2008, p. 71).

\footnotetext{
${ }^{11}$ Nas palavras de Moreira (2008a, p. 76): a religião ajudou e ainda ajuda "a modelar um sistema de lealdades e identidades, e esse sistema agora está mais complexo e competitivo".
} 
Religare, ISSN: 19826605, v.16, n.2, dezembro de 2019, p.692-713

Na esfera da religião, essa rede propagandista é responsável pelo processo de amortização ${ }^{12}$ do indivíduo em relação à mercadoria. Em certa proporção esse processo que envolve uma realidade fidelizante contribui com a formatação identitária do sujeito religioso, ainda que nessa estrada peregrina o indivíduo de certa forma perca sua alma ${ }^{13}$ (MOREIRA, 2015, grifo nosso).

Esse processo fidelizatório é análogo ao marketing articulado no campo religioso brasileiro. Contudo, não é certo que essa lógica de lealdade à determinada religião se estenda em longo prazo, tão pouco impede que o sujeito religioso continue fragmentado e bebedor de todas as outras fontes de religiosidade disponíveis no mercado. Isso porque na esfera do mercado o marketing religioso tanto fideliza como desfideliza clientes.

No que tange à esfera religiosa, vivemos em um mundo ainda (re) encantado mesmo que de forma ressignificada onde a privatização do sagrado, a fluidez e dissolução do fenômeno religioso evidencia a construção de religiosidades paralelas, não institucionalizadas (GUERRIERO, 2004, p. 159-169). Configura-se assim a paisagem religiosidades peregrinas, bricoladas, flutuantes e destradicionalizada (HERVIEU-LÉGER, 2008). Nesse aspecto, de forma antagônica ao processo de fidelização, abrem-se os pressupostos para a identificação de um processo paralelo de desfidelização que está relacionado à fragilização dos vínculos religiosos. Com razão afirma Bauman que os sujeitos de hoje possuem "a capacidade de esquecer e descartar prontamente antigos ativos transformados em passivos, assim como a capacidade de mudar cursos e trilhas imediatamente e sem remorso" (BAUMAN apud MARINUCCI, 2010, p. 138).

Tal realidade descartável também ocorre ao passo que vivemos uma religiosidade a mercê das propagandas. Configuramos nossas experiências nos

\footnotetext{
12 "O marketing, indo muito além das vitrines dos antigos boulevards, através do design e do emprego contínuo dos artistas plásticos ou visuais, se encarregou de amorizar o comprador com o objeto, de criar nos passantes o que W. Benjamin chamou de empatia com a mercadoria" (MOREIRA, 2015, p. 385).

${ }^{13}$ Nesse processo "a entusiástica adesão ou doação de si da pessoa à superfície cuidadosamente estetizada da mercadoria doa a esta uma alma, enquanto o comprador perde a sua" (MOREIRA, 2015, p. 386).
} 
Religare, ISSN: 19826605, v.16, n.2, dezembro de 2019, p.692-713

espaços onde quem dá mais, é por nossas almas. E, diante desse campo religioso diluído que os fieis brasileiros transitam e se instalam dentro de determinada confissão religiosa. Tendo em vista esse contexto, talvez a perda da memória autorizada (HERVIEU-LÉGER, 2008), associada a uma memória religiosa cada vez mais curta, por uma parte, talvez possa explicar o declínio da população católica no cenário brasileiro. Por outra parte, há de se notar que tal característica do homo religiosus da modernidade também não assegura o crescimento ou a permanência dos fieis dentro das outras religiões (evangélicos e espíritas).

Dentro dessa disputa por almas, e tendo em vista as oscilações das preferências e demandas cotidianas dos sujeitos, quanto maior o acesso à mídia, maior propagação publicitária, maior o potencial de (re)conquista de novos e antigos fieis. Quiçá, por isso o público evangélico tenha crescido significativamente, e em contrapartida a população católica tenha diminuído, acionando nesse contexto uma reação urgente por parte de sua instituição. Por outra parte, o grupo dos que se dizem sem religião, mais de 15 milhões de pessoas $(8,0 \%)($ IBGE, 2010, n/p) podem ser vistos de forma não generalizada como a parcela representante mesmo que não declaradamente de "uma world -religion visível e que se pode consumir sem ter que prestar contas às instituições tradicionais de tipo religioso" (PACE, 1997, p. 34-35).

Todas essas informações nos colocam frente a um panorama onde a simbiose entre marketing e mobilidade religiosa está longe de ser totalmente decifrada. No que concerne à paisagem de fé brasileira, ao final, pretendemos como pesquisadores, tão somente 'anunciar', e porque não, divulgar, ou melhor 'propagandizar' alguns dos elos de uma corrente não tão 'invisível' ou frágil como aparenta ser. Nisto ainda consiste nosso trabalho.

\section{Conclusão}

A teoria do campo religioso se constitui em um mosaico de complexidades. No que concerne às novas tendências e movimentações das 
Religare, ISSN: 19826605, v.16, n.2, dezembro de 2019, p.692-713

estruturas religiosas em seu interior apontamos o marketing religioso como uma estratégia de sobrevivência institucional, bem como ferramenta midiática de competitividade dentro de um mercado religioso que se reconfigura. Sob essa perspectiva, a tendência de cooptar estruturas do mercado secular fornece à própria religião um argumento propagandístico que implica no quadro de mobilidade religiosa no cenário brasileiro. Nesse contexto mercadológico que envolve um clima de alta competitividade, a partir de uma evidenciação análoga entre marketing e religião propomos a reflexão existencial de alguns prováveis elos entre o marketing e a mobilidade religiosa no campo religioso brasileiro contemporâneo.

O primeiro elo hipotético que vislumbramos toma forma a partir do processo de psicologização do mercado religioso. Em nossa concepção, tal ordenamento psicologizante que trabalha principalmente com sentimentos humanos promove um status de empatia entre cliente e mercadoria. No caso específico do campo religioso brasileiro, com todas as ressalvas às políticas investigativas e interpretativas androcêntricas e patriarcais, o crescimento de uma população evangélica predominantemente feminina suscita uma investigação mais acurada acerca das possíveis conexões entre marketing, gênero e mobilidade religiosa.

O segundo elo entre marketing e mobilidade religiosa se estabelece na medida em que a midiatização das promessas que respondem aos problemas do 'aqui e agora', 'deste mundo' tem interferido e atuado como vetor de mobilidade religiosa no Brasil. Nesse cenário, a estratificação das demandas e preferências, bem como o aumento ou declínio das religiões está diretamente ligada com o quadro de estratificação social que nos rodeia.

O terceiro elo entre marketing e mobilidade religiosa é construído na medida em que a estruturação identitária promovida pelo marketing religioso também se caracteriza como fator de mobilidade religiosa. Nessa paisagem, as religiões brasileiras com maior alcance e potencial de empatia são responsáveis 
Religare, ISSN: 19826605, v.16, n.2, dezembro de 2019, p.692-713

pela (re)construção identitária dos fieis que se deslocam em busca de mais um fragmento identitário em meio a uma sociedade de faces e identidades religiosas múltiplas e fluídas. Dentro desse mosaico identitário, o marketing religioso fomenta tanto um processo de fidelização quanto de desfidelização.

Nesse panorama propagandista e imediatista onde só quem é visto é lembrado, aqueles que têm maior espaço na mídia possuem grande probabilidade de alcançar mais clientes; estes por outro lado, fieis não sabemos até quando. Em tempos da marketização do campo religioso, talvez até a próxima 'oferta', ou promessa de uma vida livre de aflições e problemas.

Ao final de nossa investigação, a constatação desses elos, por uma parte, nos indica um caminho complexo a percorrer no que tange a empresa analítica do fenômeno religioso no panorama brasileiro atual. Aqui, procuramos apenas trazer à tona o espectro dialógico entre marketing e mobilidade religiosa. Por outra parte, em uma época de religiosidades peregrinas e fragmentárias em que o espectro identitário do homo religiosos e homo economicus se fundem, somente o tempo e a ciência poderão nos dizer se esses elos são estruturas frágeis ou titânicas. Mas isto, deixaremos para as cenas de um capítulo próximo. Para os balcões existenciais de uma próxima propaganda da vida humana.

\section{Referências}

ALBUQUERQUE, Leila Marrach Basto de. Estrutura e dinâmica dos novos movimentos religiosos. In: SOUZA, Beatriz Muniz de; MARTINO, Luís Mauro Sá (Orgs.). Sociologia da religião e mudança social: católicos, protestantes e novos movimentos religiosos no Brasil. São Paulo: Paulus, 2004. p. 139-150.

BAUMAN, Zygmunt. O mal-estar da pós-modernidade. Rio de Janeiro: Zahar, 1998. BERGER, Peter. O dossel sagrado: elementos para uma teoria sociológica da religião. Trad. José Carlos Barcelos. São Paulo: Paulinas, 1985.

BOURDIEU, Pierre. A economia das trocas simbólicas. Organização Sérgio Moceli. São Paulo: Perspectiva, 1974.

EINSTEIN, Mara. Brands of Faith. Marketing religion in a commercial age. New York: Routledge, 2008.

GUERRA, Danilo Dourado. Do além para o mundo: perspectivas sobre mobilidade religiosa no Brasil da pós-modernidade. Fragmentos de Cultura. Goiânia, v. 24, n. 1, p. 115-123, jan.-mar. 2014. 
Religare, ISSN: 19826605, v.16, n.2, dezembro de 2019, p.692-713

GUERRIERO, Silas. A visibilidade das novas religiões no Brasil. In: SOUZA, Beatriz Muniz de; MARTINO, Luís Mauro Sá (Orgs.). Sociologia da religião e mudança social: católicos, protestantes e novos movimentos religiosos no Brasil. São Paulo: Paulus, 2004. p. 157-163.

GOUVEIA, Eliane Hojaij. Apontamentos sobre novos movimentos religiosos. In: SOUZA, Beatriz Muniz de; MARTINO, Luís Mauro Sá (Orgs.). Sociologia da religião e mudança social: católicos, protestantes e novos movimentos religiosos no Brasil. São Paulo: Paulus, 2004. p. 151-156.

HERVIEU-LÉGER, Daniele. O peregrino e o convertido. A religião em movimento. Petrópolis: Vozes, 2008.

MARINUCCI, Roberto. Construção da identidade religiosa em contexto migratório: o caso da migração para o DF-Brasil. Revista Internacional de Mobilidade Humana. Brasília, ano XVIII, n. 34, p. 131-148, jan.-jun. 2010.

MOREIRA, Alberto da Silva. O deslocamento do religioso na sociedade contemporânea. São Paulo. Estudos de Religião. n. 34, p. 70-83, jan.-jun. 2008.

Empresas de salvação e capitalismo do imaginário como desafio à sociologia da religião. Goiânia. Caminhos. v. 6, n. 1, jan.-jun. 2008b. p. 127-158.

2012.

. A religião na mídia e a mídia na religião. Goiânia: Gráfica e editora América,

A religião sob o domínio da estética. Belo Horizonte. Revista Horizonte, vol. 13, no. 37, p. 379-405, jan.-mar. 2015.

PACE, Enzo. Religião e globalização. In: NER-Núcleo de Estudos da religião. Petrópolis: Vozes, 1997. p. 25-38.

PRANDI, Reginaldo. A religião do planeta global. In: NER-Núcleo de Estudos da religião. Petrópolis: Vozes, 1997.

PUNTEL, Joana T. Cultura midiática e igreja: uma nova ambiência. São Paulo: Paulinas, 2005.

RIBEIRO, Claudio de Oliveira. Um olhar sobre o atual cenário religioso brasileiro: possibilidades e limites para o pluralismo. São Paulo. Estudos de Religião. v. 27, n. 2, p. 53-71, jul.-dez. 2013.

SEGATO, Rita Laura. Formações de diversidade: Nação e opções religiosas no contexto da globalização. In: NER-Núcleo de Estudos da religião. Petrópolis: Vozes, 1997.

SOUZA, Beatriz Muniz de e MARTINO, Luís Mauro Sá (Orgs.). Sociologia da religião e mudança social. São Paulo: Paulus, 2004.

VELHO, Otávio. Globalização: Antropologia e religião. In: NER-Núcleo de Estudos da religião. Petrópolis: Vozes, 1997.

CENSO DEMOGRÁFICO 2010: características gerais da população, religião e pessoas com deficiência. Disponível: $<$ https://biblioteca.ibge.gov.br/visualizacao/periodicos/94/cd_2010_religiao_defi ciencia.pdf>. Acesso em: 22 jul. 2019.

Recebido em 19-06-2019.

Aprovado em 01-08-2019. 